\title{
Prediction of Return to Work after Mild Traumatic Brain Injury by Different Assessment Scales
}

\author{
AMANY S. HASSAN, M.Sc.*; EMAN S.M. FAYEZ, Ph.D.**; AHMED EL FIKI, Ph.D.*** and \\ AHMED S. ALI, M.D.** \\ The Department of Physical Therapy Emergency Hospital, Faculty of Medicine, Cairo University*, \\ The Department of Physical Therapy for Neuromuscular Disorders \& its Surgery, Faculty of Physical Therapy** and \\ The Department of Neurosurgery, Faculty of Medicine***, Cairo University
}

\begin{abstract}
Background: Mild Traumatic Brain Injury (m-TBI) based on a score of 15 on the Glasgow Coma Scale; a score of 13 or 14 is due to confusion and will be associated with a long duration of posttraumatic amnesia. Identifying factors that increase the risk of m-BTI is necessary to develop public health programs and reduce the risk of being unable to return to work. Therefore, early detection of disability and intervention training is a very important treatment strategy to enable the injured patients to return to their works.
\end{abstract}

Aim of Study: Is to predict disability effect on Return to Work (RTW) by assessment scales for patients with mild traumatic brain injury during hospital stay and eight to twelve weeks follow-up.

Material and Methods: Different assessment scales including; Glasgow Coma Scale (GCS), the Montreal Cognitive Assessment (MOCA) Arabic Version, Disability Rating Scale (DRS) and Post Traumatic Amnesia Time (PTAT) were reported a detailed understanding of patients temporally changes in physical and mental statues and its impact on successful RTW and community integration. A prospective cohort study of sixty-one patients with mild traumatic brain injury (mTBI) admitted consecutively to Neurotrauma Departments at Emergency Hospital, in El-Kasr El-Aini Hospital.

Results: The results revealed that return to work and recovery from $\mathrm{m}$-TBI occurred after hospital discharging between eight to twelve weeks in 6 patients $(9.8 \%)$, six to eight weeks in 28 patients $(45.9 \%)$, two to four weeks in 9 patients $(14.8 \%)$ and one week in 18 patients $(29.5 \%)$ and this was supported by using GCS, MOCA [highly predicted $(94.86 \%)$ ] and DRS [highly predicted (96.03\%)] scales to predict and develop a suitable work plan according to patient disability.

Conclusion: Return to work and recovery from mild traumatic brain injury occurred mainly between six and eight weeks and were followed for twelve weeks post-traumatic, indicating a high rate of predictability using GCS, MOCA,

Correspondence to: Dr. Amany S. Hassan, The Department of Physical Therapy Emergency Hospital, Faculty of Medicine, Cairo University
DRS and PTAT and helped to develop a remedial plan suitable for disability reasons.

Key Words: Mild traumatic brain injury - The glasgow coma scale (GCS) - Disability rating scale-Montreal cognitive assessment - Post traumatic amnesia time.

\section{Introduction}

MILD traumatic brain injury is a common form of head injury, affecting about 600 per 100,000 persons at least per year globally, road traffic accidents account for most of the traumatic brain injuries. Most m-TBI patients return to previous work independently despite some patients may have mild cognitive disability $[\mathbf{1 , 2}]$.

Employment is participating in difficult aspects of life. Working people with head injury report better mental statues, social integrity and better life quality than people without employment [5-8]

The National Institute on Disability and Rehabilitation Research (NIDRR) and Traumatic Brain Injury Model Systems (TBIMS) stated that only $22 \%$ of TBI patients had return to work during first year after injury [3]. Fifteen different research studies found that, eighty to ninety of unemployment cases were reported during rehabilitation period after acute brain injury [4]

\footnotetext{
Abbreviations:

m-TBI : Mild Traumatic Brain Injury.

GCS : Glasgow Coma Scale.

PTAT : Post Traumatic Amnesia Time.

MOCA : Montreal Cognitive Assessment.

RTW : Return to Work.

DRS : Disability Rating Scale.
} 
The Glasgow Coma Scale (GCS) is widely used by neurosurgeons to evaluate conscious level of traumatic brain patient [9], while Disability Rating Scale (DRS) intend to measure general functional changes over the course of recovery [10]. The Montreal Cognitive Assessment (MOCA) is screening tool for cognitive impairment with very good sensitivity [11]

The purpose of this study was the relation between these assessment scales and return to work in patients with $\mathrm{m}$-TBI in terms of prediction and time needed to return to work.

\section{Material and Methods}

A prospective cohort study was done on sixtyone patients of $\mathrm{m}$-TBI who were admitted to Neurotrauma Unit, Faculty of Medicine, Al-Kasr AlAini Hospital during period from September 2018 to February 2019 during hospital stay.

Subjects:

Sixty-one patients finished our complete study assessment and follow-up, while nineteen patients refused to continue follow-up and one patient die two weeks after discharge from non-trauma related cause, suspected sudden cardiac arrest. Fifty-eight patients $(95.1 \%)$ were males while only three females $(4.9 \%)$. Age of the majority $(72.1 \%)$ of our cases ranged between twenty-one to forty years (44 patients). Fifty-one patients $(83.6 \%)$ were educated (Technical Education) while only ten patients $(16.4 \%)$ were illiterate. Thirty-six patients $(59 \%)$ were manual workers (driver and hand crafts) while twenty-five patients $(41 \%)$ were employed in non manual works (lawyers, social workers and security). Patients included in the study were required to have recent traumatic brain injury with GCS score [13-15] and age is more than 21 years. As in (Table 1).

\section{Procedures:}

The physiotherapist conducted clinical assessment by The Glasgow Coma Scale (GCS) Fig. (1), Post Traumatic Amnesia Time (PTAT) Fig. (2), the Montreal Cognitive Assessment (MOCA) Figs. $(3,4)$ and Disability Rating Scale (DRS) Fig. (5) based on the medical files, clinical interviews of patients and by phone calls during eight to twelve weeks were the patients asked to recall events retrospectives.

\begin{tabular}{|c|c|c|c|c|c|c|}
\hline \multicolumn{7}{|c|}{ Glasgow Coma Scale } \\
\hline & 1 & 2 & 3 & 4 & 5 & 6 \\
\hline Eye & Does not open eyes & $\begin{array}{l}\text { Opens eyes in response to } \\
\text { painful stimuli }\end{array}$ & $\begin{array}{l}\text { Opens eyes in response } \\
\text { to voice }\end{array}$ & \multicolumn{2}{|c|}{ Opens eyes spontaneously N/A } & N/A \\
\hline \multicolumn{2}{|c|}{ Verbal Makes no sounds } & Incomprehensible sounds & $\begin{array}{l}\text { Utters inappropriate } \\
\text { words }\end{array}$ & Confused, disoriented & $\begin{array}{l}\text { Oriented, } \\
\text { converses } \\
\text { normally }\end{array}$ & N/A \\
\hline \multicolumn{2}{|c|}{$\begin{array}{l}\text { Motor Makes no } \\
\text { movements }\end{array}$} & $\begin{array}{l}\text { Extension to painful stimuli } \\
\text { (decerebrate response) }\end{array}$ & $\begin{array}{l}\text { Abnormal flexion to } \\
\text { painful stimuli } \\
\text { (decorticate response) }\end{array}$ & $\begin{array}{l}\text { Flexion / withdrawal to } \\
\text { painful stimuli }\end{array}$ & $\begin{array}{l}\text { Localizes } \\
\text { painful stimuli }\end{array}$ & $\begin{array}{l}\text { Obeys } \\
\text { commands }\end{array}$ \\
\hline
\end{tabular}

Fig. (1): Glasgow coma scale. Brain injury is classified as: (A) Severe, with GCS <9. (B.C) Moder ate, GCS 9 minor, GCS > 13.

\begin{tabular}{ll}
\hline Duration of PTA & Severity \\
\hline$<5$ minutes & Very mild \\
$5-60$ minutes & Mild \\
$1-24$ hours & Moderate \\
$1-7$ days & Severe \\
$1-4$ weeks & Very severe \\
$>4$ weeks & Extremely severe \\
\hline
\end{tabular}

Fig. (2): Severity of post Traumatic Amnesia Time. PTAT include assess orientation, questions, together with questions that a response time measure, a visual acknowledgment test and a speed of response.
The Disability Rating Scale (DRS) is primarily used to assess impairment based on the Glasgow coma Scale. Disability assesses the cognitive ability of the individual after assessment by Montreal Cognitive Assessment (MOCA) Arabic version which submitted by patient his/her own and handicap of an individual.

All tests were performed in an inpatient rehabilitation setting to predict ability to return to employment based on admission and discharge". The intent of the scales was to measure the general functional changes of the patient throughout the course of recovery. 


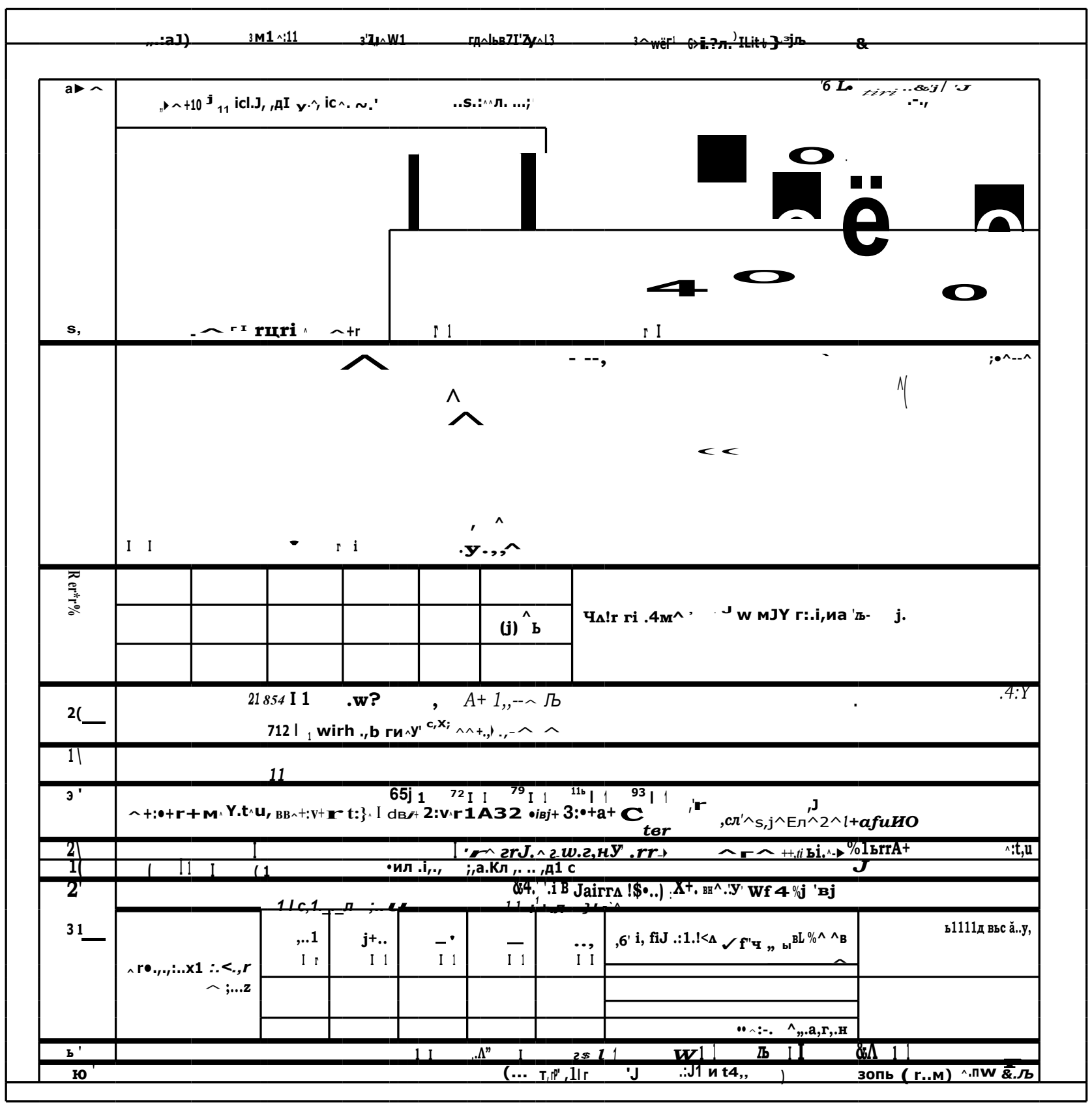

Fig. (3): Montreal Cognitive Assessment (MOCA) Arabic version. Scores range from zero to 30, with a score of 26 and higher generally considered normal.

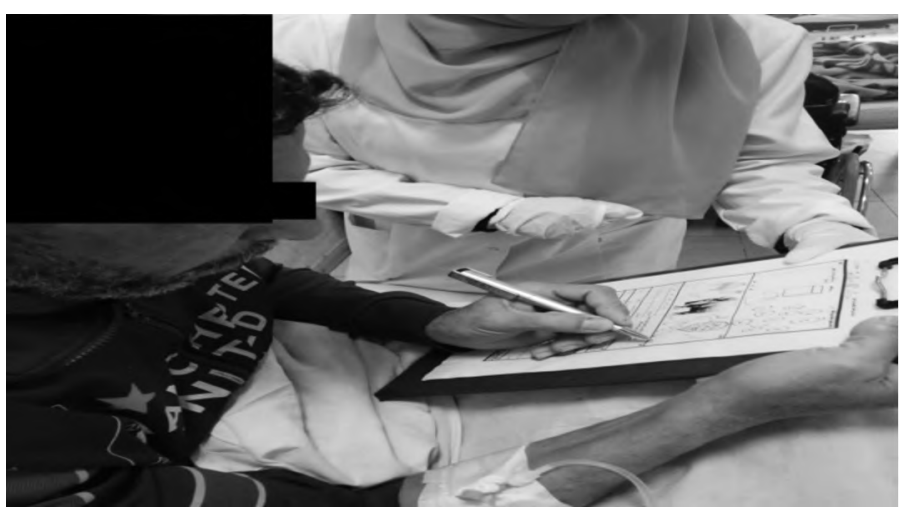

Fig. (4): Mild Traumatic Brain Injury Patient is submitting Montreal Cognitive Assessment (MOCA) Arabic version. 
Patient Name

Rater

Date Completed

\section{Diability Rating Scale (DRS)}

\section{Arousability, Awareness, \& Responsivity}

Eye Opening

U 0 Spontaneous

U 1 To Speech

U 2To Pain

U 3 None

U 0 Oriented

U 1 Confused

U 2 Inappropriate
Communication Ability

U 3 Incomprehensible

U4 None

\section{Cognitive Ability for Self Care Activities}

Knows how and when to feed, toilet or groom self
Feeding
Toileting
U 0.0 Complete
$\cup 0.5$
U 1.0 Partial
U 1.5
U 2.0 Minimal
U 2.5
U 3.0 None
U 0.0 Complete
U 0.5
U 1.0 Partial
$\mathrm{U} 1.5$
U 2.0 Minimal
U 2.5
U 3.0 None

\section{Dependence on Others}

Level of Functioning

Physical \& cognitive disability

U 0.0 Completely Independent

U 0.5

U 1.0 Independent in special environment

$\mathrm{U} 1.5$

U 2.0 Mildly Dependent-Limited assistance Non-resident helper

$\mathrm{U} 2.5$

U 3.0 Moderately Dependent-moderate assist Person in home

U 3.5

U 4.0 Markedly Dependent

Assistance with all major activities, all times

U 4.5

J 5.0 Totally Dependent

24 hour nursing care

\section{Total Score (sum all scores)}

Revised 2/99 Santa Clara Valley Medical Center

\author{
Motor Response \\ $\mathrm{U} 0$ Obeying \\ $\mathrm{U} 1$ Localizing \\ U 2 Withdrawing \\ U 3 Flexing \\ U 4 Extending \\ U 5 None
}
Grooming
U 0.0 Complete
$\mathrm{U} 0.5$
U 1.0 Partial
U 1.5
U 2.0 Minimal
$\mathrm{U} 2.5$
U 3.0 None

\section{Psychosocial Adaptability} Employability

As lull time worker, homemaker, student

U 0.0 Not Restricted

U 0.5

U 1.0 Selected jobs, competitive

U 1.5

U 2.0 Sheltered workshop, Noncompet.

$\mathrm{U} 2.5$

U 3.0 Not Employable

Fig. (5): The Disability Rating Scale (DRS).

\begin{tabular}{cl}
\hline Total DRS score & Level of disability \\
\hline 0 & None \\
1 & Mild \\
$2-3$ & Partial \\
$4-6$ & Moderate \\
$7-11$ & Moderately severe \\
$12-16$ & Severe \\
$17-21$ & Extremely severe \\
$22-24$ & Vegetative state \\
$25-29$ & Extreme vegetative state \\
30 & Death \\
\hline
\end{tabular}

Fig. (6): Disability categories, total DRS score, level of disability. The maximum score a patient can obtained on the DRS is 29 (extreme vegetative state). A person without disability would score zero.

Abbreviation: DRS: Disability Rating Scale. 


\section{Statistical analysis:}

The statistical analysis was conducted by using statistical SPSS Package program Version 20 for Windows (SPSS, Inc., Chicago, IL). The following statistical procedures were conducted:

Descriptive statistics: Including the number and percentage for all variables.

- Chi-square test: Used to compare between during hospital stay and after discharge for scales. Also, to compare between patients returned to work and those had not returned to work within prediction and actually returned to work for scales.

- Spearman rank correlation: For prediction between scales and returned to work.

- Significant level: All statistical analyses were significant at $p \prec 0.05$.

\section{Results}

Sixty-one patients finished our complete study assessment and follow-up, while nineteen patients refused to continue follow-up and one patient die two weeks after discharge from non-trauma related cause, suspected sudden cardiac arrest. Fifty-eight patients $(95.1 \%)$ were males while only three females $(4.9 \%)$. Age of the majority $(72 \%)$ of our cases ranged between twenty-one to forty years (44 patients). Fifty-one patients $(83.6 \%)$ were educated (Technical Education) while only ten patients $(16.4 \%)$ were illiterate. Thirty-six patients $(59 \%)$ were manual workers (driving and hand crafts) while twenty-five patients $(41 \%)$ were employed in non manual works (lawyers, social workers and security).

Different modes of trauma were encountered in our study including; road traffic collusions in twenty-eight patients (45.9\%), fights in fourteen patients $(22.9 \%)$, falling from height in twelve patients $(19.7 \%)$ and work related injury in seven patients $(11.5 \%)$ as shown in (Table 1$)$.

Glasgow Coma Scale (GCS) during hospital stay were 15 in forty-seven patients (77\%), 14 in eight patients (13.1\%) and 13 in six patients $(9.8 \%)$. While all patients were discharged within three days fully conscious (GCS 15). Patients with very mild grade Post Traumatic Amnesia (PTAT) were thirty-seven $(60.7 \%)$ and very sever grade were in one patients $(1.6 \%)$ as shown in (Table 2$)$.

The Montreal Cognitive Assessment (MOCA) scale revealed that during hospital stay, two patients $(3.3 \%)$ had cognitive impairment and only one of them improved two weeks after leaving the hospital and the rest of patients (fifty-nine patients) didn't experience any cognitive impairment during hospital stay or follow-up period as shown in (Table 2).

Table (1): Demographic data.

\begin{tabular}{|c|c|c|}
\hline Items & Number & Percentage \\
\hline \multicolumn{3}{|l|}{ Sex: } \\
\hline Male & 58 & $95.1 \%$ \\
\hline Female & 3 & $4.9 \%$ \\
\hline \multicolumn{3}{|l|}{ Age: } \\
\hline 21-40 year & 44 & $72.1 \%$ \\
\hline $40-50$ year & 8 & $13.1 \%$ \\
\hline $50-65$ year & 9 & $14.8 \%$ \\
\hline \multicolumn{3}{|l|}{ Education: } \\
\hline Educated & 51 & $83.6 \%$ \\
\hline Illiterate & 10 & $16.4 \%$ \\
\hline \multicolumn{3}{|l|}{ Employed category: } \\
\hline Non manual works & 25 & $41 \%$ \\
\hline Manual works (hand crafts, driving) & 36 & $59 \%$ \\
\hline \multicolumn{3}{|l|}{ Smoking: } \\
\hline Yes & 39 & $63.9 \%$ \\
\hline No & 22 & $36.1 \%$ \\
\hline \multicolumn{3}{|l|}{ Drug abuse: } \\
\hline Yes & 4 & $6.6 \%$ \\
\hline No & 57 & $93.4 \%$ \\
\hline \multicolumn{3}{|l|}{ Cause of injury: } \\
\hline Road traffic collision & 28 & $45.9 \%$ \\
\hline Fights & 14 & $22.9 \%$ \\
\hline Falling from height & 12 & $19.7 \%$ \\
\hline Work related injury & 7 & $11.5 \%$ \\
\hline
\end{tabular}

Table (2): Comparison of scales between during hospital stay and recovery after discharge.

\begin{tabular}{|c|c|c|c|c|}
\hline Scales & $\begin{array}{c}\text { During } \\
\text { hospital stay } \\
(1-3 \text { days }) \\
(n=61)\end{array}$ & $\begin{array}{c}\text { After } \\
\text { discharge } \\
(1-12 \text { weeks }) \\
(\mathrm{n}=61)\end{array}$ & $\begin{array}{c}x^{2-} \\
\text { value }\end{array}$ & $\underset{\text { value }}{p^{-}}$ \\
\hline \multicolumn{5}{|l|}{$G C S:$} \\
\hline - 13 & $6 \quad(9.8 \%)$ & $0(0 \%)$ & 15.815 & 0.0001 \\
\hline - 14 & $8 \quad(13.1 \%)$ & $0(0 \%)$ & & \\
\hline - 15 & $47(77.0 \%)$ & $61(100 \%)$ & & \\
\hline \multicolumn{5}{|l|}{ PTAT: } \\
\hline • (Very mild) none & $37(60.7 \%)$ & & & \\
\hline - $($ Mild $)<5$ minutes & $4 \quad(6.6 \%)$ & & & \\
\hline - (Moderate) 5-60 minutes & $15(24.6 \%)$ & & & \\
\hline • (Sever) 1-24 hours & $4 \quad(6.6 \%)$ & & & \\
\hline • (Very sever) 1-4 weeks & $1 \quad(1.5 \%)$ & & & \\
\hline \multicolumn{5}{|l|}{$M O C A:$} \\
\hline - Normal control $(>26)$ & $59(96.7 \%)$ & $60(98.4 \%)$ & 0.342 & 0.559 \\
\hline $\begin{array}{l}\text { - Cognitive impairment } \\
(<26)\end{array}$ & $2 \quad(3.3 \%)$ & $1 \quad(1.6 \%)$ & & \\
\hline \multicolumn{5}{|l|}{ DRS: } \\
\hline - None & $51(83.6 \%)$ & $39(63.9 \%)$ & 32.679 & 0.0001 \\
\hline • Mild & $4(6.6 \%)$ & $4 \quad(6.6 \%)$ & & \\
\hline • Partial & $3(4.9 \%)$ & $15(24.6 \%)$ & & \\
\hline - Moderate & $2(3.3 \%)$ & $2 \quad(3.3 \%)$ & & \\
\hline - Moderately sever & $1(1.6 \%)$ & $1 \quad(1.6 \%)$ & & \\
\hline
\end{tabular}


The disability rating scale scores during hospital stay was successfully able to predict that thirtynine patients $(63.9 \%)$ will be able to return to work after discharge, ten patients (16.4\%) were correctly unable to return to work according to DRS scores due to different forms of physical disabilities as shown in (Table 3).

Twelve patients (19.7\%) did not return to work although DRS during their hospital stay was suggesting their smooth return to work but in these cases it was related to other causes than head trauma (social isolation, orthopedic fractures, work related social problems) as shown in (Tables 3,4).

The statistical analysis revealed that there were significant differences $(p=0.0001 ; p<0.05)$ in scales (GCS and DRS) while no significant difference $(p=0.559 ; p>0.05)$ in MOCA scale between patients during hospital stay and recovery after discharge to returned to work.

Table (3): Prediction versus actually returned to work within returned and not returned to work.

\begin{tabular}{|c|c|c|c|c|}
\hline \multirow{2}{*}{ Scales } & \multicolumn{2}{|c|}{ Returned to work } & \multicolumn{2}{|c|}{ Not returned to work } \\
\hline & Prediction & Actually & Prediction & Actually \\
\hline Return to work: & $51(83.6 \%)$ & $39(63.9 \%)$ & $10(16.4 \%)$ & $22(36.1 \%)$ \\
\hline$\cdot \chi^{2}$-value & 10.588 & & 5.697 & \\
\hline$\cdot p$-value & 0.005 & & 0.034 & \\
\hline \multicolumn{5}{|l|}{$M O C A:$} \\
\hline - $\begin{array}{l}\text { Normal control } \\
(>26)\end{array}$ & $59(96.7 \%)$ & $60(98.4 \%)$ & $0(0 \%)$ & $0(0 \%)$ \\
\hline $\begin{array}{l}\text { - Cognitive } \\
\text { impairment } \\
\left(\varsigma_{2} 26\right)\end{array}$ & $1(1.6 \%)$ & $0(0.0 \%)$ & $1(1.6 \%)$ & $1(1.6 \%)$ \\
\hline$\cdot \chi^{2}$-value & 0.992 & & 0.000 & \\
\hline$\cdot p$-value & 0.319 & & 1.000 & \\
\hline \multicolumn{5}{|l|}{$D R S:$} \\
\hline • None & $39(100 \%)$ & $39(100 \%)$ & $10(0 \%)$ & $10(0 \%)$ \\
\hline $\begin{array}{l}\text { - Independent in } \\
\text { special } \\
\text { environment }\end{array}$ & $0(0 \%)$ & $0(0 \%)$ & $4(100 \%)$ & $4(100 \%)$ \\
\hline - Selected jobs & $0(0 \%)$ & $0(0 \%)$ & $2(100 \%)$ & $2(100 \%)$ \\
\hline $\begin{array}{l}\text { - Mildly } \\
\text { dependent }\end{array}$ & $0(0 \%)$ & $0(0 \%)$ & $1(100 \%)$ & $1(100 \%)$ \\
\hline $\begin{array}{l}\text { Markedly } \\
\text { dependent }\end{array}$ & $0(0 \%)$ & $0(0 \%)$ & $2(100 \%)$ & $2(100 \%)$ \\
\hline $\begin{array}{l}\text { - Totally } \\
\text { dependent with } \\
\text { inappropriate } \\
\text { response }\end{array}$ & $0(0 \%)$ & $0(0 \%)$ & $1(10.0 \%)$ & $1(10.0 \%)$ \\
\hline$\cdot \chi^{2}$-value & 0.000 & & 0.000 & \\
\hline •p-value & 1.000 & & 1.000 & \\
\hline
\end{tabular}

Table (4): Causes related to not return to work and time of return to work after injury.

\begin{tabular}{lccc}
\hline Items & $\begin{array}{c}\text { Number } \\
(\%)\end{array}$ & $\begin{array}{c}\chi^{2}- \\
\text { value }\end{array}$ & $\begin{array}{c}p^{-} \\
\text {value }\end{array}$ \\
\hline $\begin{array}{l}\text { Causes related to not return to work } \\
(n=22):\end{array}$ & & & \\
Work related disability & $3(13.6 \%)$ & 7.928 & 0.041 \\
Work related psychological cause & $6(27.3 \%)$ & & \\
Orthopedic fracture injury & $8(36.4 \%)$ & & \\
$\quad$ Persistence PCS & $5(22.7 \%)$ & & \\
\hline
\end{tabular}

For those 39 cases who returned to work, the relation between Post Traumatic Amnesia Time and time to return to work was documented in (Table 5) showing that 23 patients $(59 \%)$ returned to work with 6-8 weeks with very mild grade of amnesia (fourteen patients) and moderate grade of amnesia (nine cases). Only three cases (7.7\%) with sever grade of amnesia and returned to work within $8-12$ weeks. And the rest of patients (13 cases) returned to work within 1-4 weeks as shown in (Table 5).

Results indicated that Montreal Cognitive Assessment (MOCA) $(p=0.891 ; p>0.05)$ and Disability Rating (DRS) $(p=0.902 ; p>0.05)$ scales could be significantly predicted from assessing the cognitive status and ability to track an individual from coma to community as shown in (Table 6).

Table (5): Post Traumatic Amnesia Time (PTAT) grades and time of return to work after injury.

\begin{tabular}{lccccc}
\hline PTAT & $\begin{array}{c}\text { Very mild } \\
\text { (none) }\end{array}$ & Mild & Moderate & Sever & $\begin{array}{c}\text { Very } \\
\text { sever }\end{array}$ \\
\hline 1 week & $3 \quad(7.7 \%)$ & & & & \\
2-4 weeks & $6(15.4 \%)$ & $4(10.2 \%)$ & & & \\
6-8 weeks & $14(35.9 \%)$ & & $9(23.1 \%)$ & & \\
8-12 weeks & & & & $3(7.7 \%)$ & $0(0.0 \%)$ \\
\hline
\end{tabular}

Table (6): Overall prediction of scales related to mild Traumatic Brain Injury (m-TBI).

\begin{tabular}{lll}
\hline \multirow{2}{*}{ Item } & \multicolumn{2}{c}{ Scales } \\
\cline { 2 - 3 } & MOCA & DRS \\
\hline Prediction & $94.86 \%$ & $96.03 \%$ \\
$p$-value & 0.891 & 0.902 \\
Significant & NS* & NS* \\
\hline
\end{tabular}

*: Non significant difference.

\section{Discussion}

Return to work is an essential result proportion of TBI. It has been underlined as a key part for assessing result in the World Health Organization's International Classification of Functioning, Disability and Health. Unsuccessful RTW can have significant negative financial and psychosocial ramifications for TBI patients and their families [12] .

Returning to work will depend on how patients are feeling, associated injury related disability and the type of job that they do. As the symptoms may impede carrying out the responsibility at work. So the issue of the present study is to predict disability (during hospital stay) versus ability of return to work (during recovery after discharge) by assessment scales for patients with mild traumatic brain 
injury to be taken into consideration when evaluating future occupational rehabilitation.

It was very noticeable in this study that the increase in the number of males than the number of females in m-TBI injury cases, which was consistent with the studies that examined the population of m-BTI found that the risk of TBI among males is twice the risk among females. The real reasons for $\mathrm{m}$-TBI are: Car collusion, violence, particularly suicidal behavior and assaults involving firearmsthe main source of death associated with TBI Is located the main source of TBI among the older. While others found that TBI rates were high and equal for both sexes in young age, while adult males are the group most at risk [13,14]

Glasgow Coma Scale and PTAT were measured and monitored during the period of stay in the hospital (GCS 13, 14, 15) and achieving the significant differences in the improving all participants patient conscious state to reaching GCS 15. It also indicates that the GCS score at emergency admission has a prognostic estimate [15] and that it is a vital factor in each diagnostic score [16].

Cognitive measurement and identification requires a degree of awareness of measurement and reassessment during the recovery period. There was no significant change in the proportion of patients with normal cognitive control at admission and during hospital stay. However, there was an improvement of cognitive impairment patients due to $\mathrm{m}$-TBI during recovery period. It is clear from literature [17-19] that the neuropsychological test results, as proportions of cognitive ability, have been found to associate essentially with practical result measures (e.g DRS).

As The Montreal Cognitive Assessment (MO$\mathrm{CA}$ ) was measured twice post injury and there is no significant change in the proportion of patients with cognitive impairment. As they only participant patient who presented with mild cognitive impairment was detected with more than 24 hours of post traumatic amnesia at the second time of $\mathrm{m}$-TBI (Arachnoid Cyst on the left temporal lobe) within 12 days of the first time (left temporal concussion) of $\mathrm{m}$-TBI due to vertigo, the patient falling from height and cause second TBI.

We could have excluded this patient from our study, but he was among the participants in the included criteria when he was first injured. This indicates that minor head trauma can cause a cyst damage as a complications of arachnoids cysts [20]. Which can cause the fluid within a cyst to leak into other areas (e.g., subarachnoid space).
To develop a detailed understanding of temporal change at the individual level, regarding ability of return to work, disability rating scale prediction measurement and actual status after post injury recovery was comparable and resulted in a high proportion of the two standards which is consistent with the finds of Brooks and coworkers [21].

Accordingly, most patients were able to return to their work after 6-8 weeks after injury, while only a few returned after two weeks which were the least severity of injury. On the other hand, the patient expected the possibility of returning to work, but did not return for reasons that like social isolation, orthopedic deficits and aging associated with post concussion symptoms. This is consistent with some previous studies that have reported that a mild traumatic brain injury is a unique injury that affects everyone differently. Recovery times may vary but the majority of people will notice that their symptoms are gone after a few days. however, some patient may experience prolonged recovery and take longer to return to work [22-24]

Finally, in this study, there were five patients who did not return to work despite the expectation of their return through the DRS, which were not accurate in predicting the symptoms of persistence concussion and this is what is taken on this scale in his ability to predict long-term disability in $\mathrm{m}$ TBI patients. Some sources reported that the DRS has a few disadvantages as the inter-rater reliability need to be well established [25], while others found a high variability [26].

\section{Conclusions:}

Return to work and recovery from mild traumatic brain injury occurred mainly between six and eight weeks and were followed for twelve weeks post-traumatic, indicating a high rate of predictability using GCS, MOCA (94.86\%), DRS $(96.03 \%)$ and PTAT and helped to develop a remedial plan suitable for disability reasons. Thus these findings should be taken into consideration when evaluating future occupational rehabilitation.

\section{References}

1- HOLM L., CASSIDY J.D., CARROLL L.J. and BORG J.: Summary of the WHO Collaborating Centre for Neurotrauma Task Force on Mild Traumatic Brain Injury. J. Rehabil. Med., 37: 137-41, 2005.

2- STYRKE J., STÅLNACKE B.M., SOJKA P. and BJÖRNSTIG U.: Traumatic brain injuries in a well-defined population: Epidemiological aspects and severity. J. Neurotrauma, 24: 1425-36, 2007.

3- Traumatic Brain Injury Model Systems. Information section on the database.Available from: http//www. tbims.org. 
4- MALEC J.F. and BASFORD J.S.: Postacute brain injury rehabilitation. Arch. Phys. Med. Rehabil., 77: 198-207, 1996.

5- CORRIGAN J.D., BOGNER J.A., MYSIW W.J., CLINCHOT D. and FUGATE L.: Life satisfaction after traumatic brain injury. Journal of Head Trauma Rehabilitation, 16: 543-55, 2001.

6- STEADMAN-PARE D., COLANTONIO A., RATCLIFF G., CHASE S. and VERNICH L.: Factors associated with perceived quality of life many years after traumatic brain injury. Journal of Head Trauma Rehabilitation, 16: 33042, 2001.

7- WEHMAN P., TARGETT P., WEST M. and KREGEL J.: Productive work and employment for persons with traumatic brain injury: What have we learned after 20 years? Journal of Head Trauma Rehabilitation, 20: 115-27, 2005.

8- O'NEILL J.H., ZUGER R.R., FIELDS A., FRASER R. and PRUCE T.: The program without walls: Innovative approach to state agency vocational rehabilitation of persons with traumatic brain injury. Archives of Physical Medicine and Rehabilitation, 85 (4 Suppl 2): S68-S72, 2004.

9- TAYLOR C.A., BELL J.M., BREIDING M.J. and XU L.: Traumatic brain injury-related Emergency Department visits, hospitalizations, and deaths-United States, Hagan C. Language cognitive disorganization following closed head injury: A conceptualization. In: Trexler L.E., ed. Cognitive rehabilitation: Conceptualization and intervention. New York: Plenum Press, 1982: 13 1-5, 2007, 2013.

10- BUSHNIK T.: The Level of Cognitive Functioning Scale. The Center for Outcome Measurement in Brain Injury. http://www.tbims.org/combi/lcfs ( accessed March 4, 2019), 2000.

11- World Health Organization (WHO): International Classification of Functioning, Disability and Health (ICF). Geneva, Switzerland: WHO, 2011.

12- Centers for Disease Control and Prevention: Surveillance Report of Traumatic Brain Injury-related Emergency Department Visits, Hospitalizations, and Deaths-United States, 2014. Centers for Disease Control and Prevention, U.S. Department of Health and Human Services, 2019.

13- Centers for Disease Control and Prevention (CDC), National Center for Injury Prevention and Control. Report to Congress on mild traumatic brain injury in the United States: Steps to prevent a serious public health problem. Atlanta (GA): Centers for Disease Control and Prevention, 2003.

14- MARMAROU A., LU J., BUTCHER I., McHUGH G.S., MURRAY G.D., STEYERBERG E.W., MUSHKUDIANI N.A., CHOI S. and MAAS A.I.: Prognostic value of the Glasgow Coma Scale and pupil reactivity in traumatic brain injury assessed pre-hospital and on enrollment: An IMPACT analysis. J. Neurotrauma, 24: 270-80, 2007.

15- STEYERBERG E.W., MUSHKUDIANI N., PEREL P., BUTCHER I., LU J., McHUGH G.S., MURRAY G.D., MARMAROU A., ROBERTS I., HABBEMA J.D. and MAAS A.I.: Predicting outcome after traumatic brain injury: Development and international validation of prognostic scores based on admission characteristics. PLoS Med., 5: e165; discussion e165, 2008.

16- CULLEN N.K. and WEISZ K.: Cognitive correlates with functional outcomes after anoxic brain injury: A casecontrolled comparison with traumatic brain injury. Brain Inj., 25: 35-43. [PubMed] [Google Scholar], 2011.

17- NEESE L.E., CAROSELLI J.S., KLAAS P., HIGH W.M., Jr., BECKER L.J. and SCHEIBEL R.S.: Neuropsychological assessment and the Disability Rating Scale (DRS): A concurrent validity study. Brain Inj., 14: 719-24. [Pub Med] [Google Scholar], 2000.

18- HANKS R.A., MILLIS S.R., RICKER J.H., GIACINO J.T., NAKESE-RICHARDSON R., FROL A.B., et al.: The predictive validity of a brief inpatient neuropsychologic battery for persons with traumatic brain injury. Arch. Phys. Med. Rehabil., 89: 950-7. [PubMed] [Google Scholar], 2008.

19- De K., BERRY K. and DENNISTON S.: (July): "Haemorrhage into an arachnoid cyst: A serious complication of minor head trauma". Emerg. Med. J., 19 (4): 365-6. PMC 1725893. PMID 12101165, 2002.

20- BROOKS N., CAMPSIE L., SYMINGTON C., BEATTIE A.M. and INLAY W.: The effects of severe head injury on patient and relative within seven years of injury, $\mathbf{J}$. Head Trauma Rehabil., 2: 1-13, 1987.

21- PESKIND E.R., BRODY D., CERNAK I., McKEE A. and RUFF R.L.: Military-and sports-related mild traumatic brain injury: Clinical presentation, management, and longterm consequences. J. Clin. Psychiatry, 74 (2): 180-8; quiz 188, 2013.

22- PESKIND, ELAINE R., et al.: "Military-and sports-related mild traumatic brain injury: Clinical presentation, management, and long-term consequences" Journal of clinical psychiatry Vol. 74, 2: 180-8; quiz 188, 2013.

23- PESKIND E.R., BRODY D., CERNAK I., McKEE A and RUFF R.L.: Military-and sports-related mild traumatic brain injury: Clinical presentation, management, and longterm consequences. The Journal of Clinical Psychiatry, 74 (2): 180-8; quiz 188, 2013.

24- NICHOL, et al.: Measuring Functional and Quality of Life Outcomes Following Major Head Injury: Common Scales and Checklists. Injury, Int. J., 42: 281-7, 2011.

25- SHULKA DEVI and AGRAWAL: Outcome Measures for Traumatic Brain Injury. Clinical Neurology and Neurosurgery, 113: 435-41, 2011. 


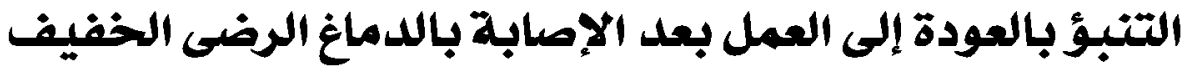

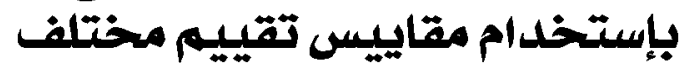

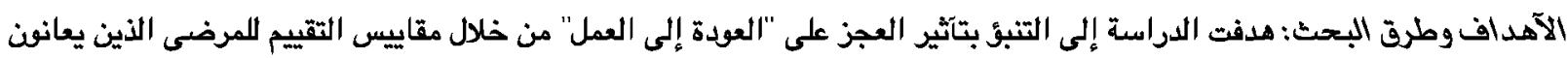

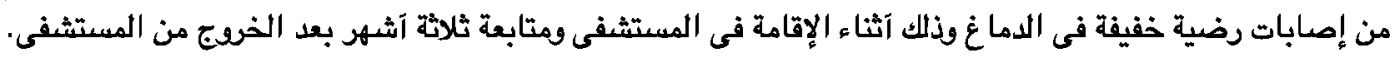

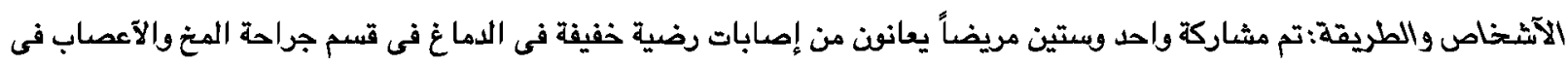

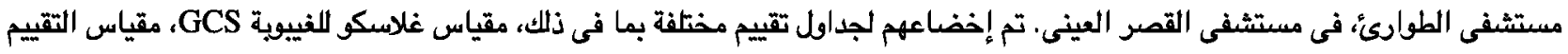

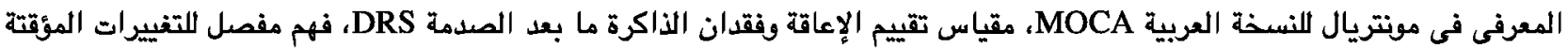
المرضى فى التماثيل الجسدية والعقلية وتآثيرها على العودة الناجحة إلى العقية العمل والتكامل.

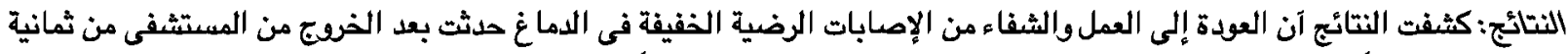

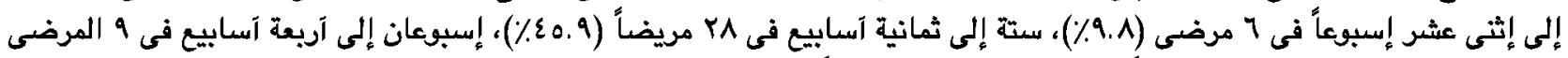

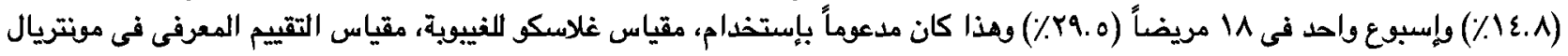

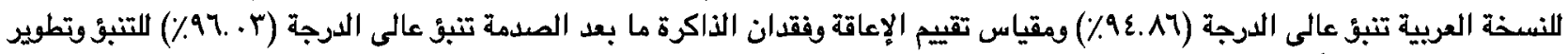
عمل خطة مناسبة وفقاً لإعاقة المريض.

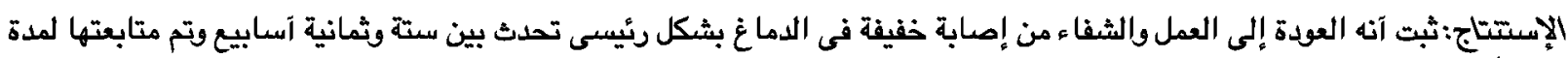

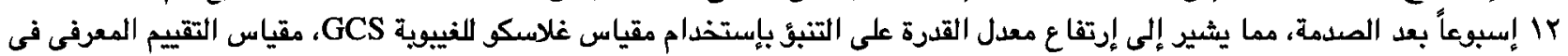

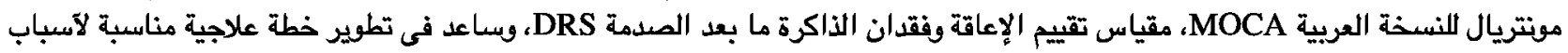

